\title{
Teenage Pregnancy and Adolescent Sexual and Reproductive Health Behavior in Suhum, Ghana ${ }^{1}$
}

\author{
Charles Quist-Adade, PhD \\ Kwantlen Polytechnic University
}

doi: 10.19044/ejes.v4no1a1ＵRL:http://dx.doi.org/10.19044/ejes.v4no1a1

\begin{abstract}
This study sought to investigate the key factors that influence teenage reproductive and sexual behaviours and how these behaviours are likely to be influenced by parenting styles of primary caregivers of adolescents in Suhum, in Eastern Ghana. The study aimed to identify risky sexual and reproductive behaviours and their underlying factors among in-school and out-of-school adolescents and how parenting styles might play a role.

While the data from the study provided a useful snapshot and a clear picture of sexual and reproductive behaviours of the teenagers surveyed, it did not point to any strong association between parental styles and teens' sexual reproductive behaviours.
\end{abstract}

Keywords: Parenting styles; parents; youth sexuality; premarital sex; teenage pregnancy; adolescent sexual and reproductive behavior.

\section{Introduction}

This research sought to present a more comprehensive look at teenage reproductive and sexual behaviours and how these behaviours are likely to be influenced by parenting styles of primary caregivers of adolescents in Suhum, in Eastern Ghana. The study aimed to identify risky sexual and reproductive behaviours and their underlying factors among inschool and out-of-school adolescents and how parenting styles might play a role. It was hypothesized that a balance of parenting styles is more likely to

1 Acknowledgements: I owe debts of gratitude to Ms. Dina Koranteng, and Mr. Atteh Grade School Teachers who assisted in the focus group discussions. I am also grateful to Kaelan Wong, my former student and research assistant at Kwantlen Polytechnic University. Finally, I thank all the students who participated in the study, the headmasters, and Assemblyman "Sasabonsam" Aboagye who assisted in the administration of the survey to parents 
produce positive sexual reproductive behaviours in young people. The research was conducted between 2009 and $2011^{2}$.

\section{Objectives}

Specific objectives of the study included:

1) To investigate the variety of parenting styles and how that impact on adolescents sexual and reproductive behavior

2) To determine teenagers' perceptions of their parents' style of parenting.

3) To investigate the level of sexual activity, contraceptive use, and pregnancy among teenagers.

4) To determine the relationships between these factors.

\section{Context}

The vulnerability of adolescents in sub-Saharan Africa to HIV is alarming as they account for almost two-thirds of those living with the disease. Their susceptibility has been attributed to a myriad of factors, in particular, risky sexual behavior. Not surprisingly, the last decade has witnessed an upsurge of research findings indicating that adolescents in many countries do not engage in safe sex practices. (Abdulraheem and Fawole, 2009; Kabiru and Orpinas, 2009; Buga, 1996; Sia, et al., 2016).Among the most salient determinants of risky behavior is family structure. Indeed, several studies in the US have emphasized the relevance of familial structure on adolescent health and reproductive outcomes. (Day, 1992; Flewelling \& Bauman, 1990; Lauritsen, 1994; Upchurch, LevyStorms, Sucoff, \& Aneshensel, 1998; Whitbeck et al., 1992; Wu \& Martinson, 1993; Young et al., 1991)

However, the bulk of this scholarship has focused on the US and other Western countries and although some progress has been made toward understanding family structures in various cultures, the scholarship has been dominated by information of Western societies. Young adults also account for a disproportionate share of new HIV infections in sub-Saharan Africa. (UNAIDS, 2008) An estimated $4.3 \%$ of young women and $1.5 \%$ of young men aged 15-24 years in Sub-Saharan Africa were living with HIV at the end of 2005. According to UNAIDS, 2014:1) "adolescent girls and young women account for one in four HIV.” .

While UNAIDS' GAP report notes HIV deaths are declining globally, it paints a somber picture of the pandemic in Africa:

"There are an estimated 24.7 million [23.5-26.1 million] people living with HIV in sub-Saharan Africa, nearly $71 \%$ of the global

2 Publication of this report was delayed due to unforeseen circumstances. 
total. Ten countries-Ethiopia, Kenya, Malawi, Mozambique, Nigeria, South Africa, Uganda, the United Republic of Tanzania, Zambia and Zimbabwe-account for 81\% of all people living with HIV in the region and half of those are in only two countriesNigeria and South Africa. There are also more women living with HIV in sub-Saharan Africa than HIV-positive men: women account for $58 \%$ of the total number of people living with HIV. There are 2.9 million [2.6 million-3.2 million] children (aged 0-14), 2.9 million [2.6 million-3.4 million] young people (aged 15-24) and more than 2.5 million [2.4 million-2.7 million] people aged 50 years and older living with HIV in sub-Saharan-Africa.” (p.28)

In the era of the AIDS pandemic, accurate monitoring of trends in risky behavior has become increasingly important as intervention programs seek to discourage premarital sexual activity ((Zaba, Whitworth , Marston, Nakiyingi, Ruberantwari, Urassa, Issingo, Mwaluko, Floyd, Nyondo and Crampin, 2005).

Adolescent premarital sexual activity is fairly common in Ghana. 54 percent of never-married male students, and 32 per cents of never-married female students (GSS, NMIMR; ORC Macro. 2004; GSS, 2003) In 1998, the Ghana Demographic Health Survey (GDHS) reported that teenage pregnancy was on the rise and that early pregnancy loss (miscarriages) among girls age 15 to 19, especially those residing in urban areas was approximately twice as high as among other women.

(GSS, MI and GDHS, 1998). At the same time, the Ghanaian premier newspaper, The Daily Graphic reported that Suhum - a town of about 50,000 residents - led the nation in the number of teenage pregnancies. (The Daily Graphic, 1998)) Four years later in 2002, the same newspaper carried a report which indicated that Suhum-Kraboa-Coaltar District3, of which Suhum is the capital, was leading the Eastern Region in teen pregnancy rates. (The Daily Graphic, 2002) The Ghana News Agency reported that in 2014 the Eastern Region recorded more 13,520 students between the ages of 12 and 15 got pregnant students (Daily Graphic Online, 2014)). The figures were obtained from the Ghana Education Service (GES). The corresponding figures for the Suhum Municipal Area is 517 pregnancies out of 5,157, the second highest in the region. The Nsawam Adoagyiri District recorded the highest of 935 pregnant girls, representing 19 per cent out of the total girls' enrolment of 4,771, in the district. (Ibid.)

3 Since this research was conducted, the Suhum-Kraboa-Coaltar District has been re-named the Suhum Municipal Area. 


\section{Research Questions:}

The study sought to answer the following five questions:

a) What roles do parenting style and family structure in fostering adolescent sexual discipline and sexual health?

b) What are the socio-cultural factors behind declining adolescent sexual discipline and sexual health?

c) What role do gender power relations and gender asymmetry play in parenting styles and how does this affect adolescents' sexual and reproductive behavior?

d) To what extent do traditional and modern methods of sex education and socialization affect adolescent sexual and reproductive behaviors?

e) How do adolescents' personal beliefs and convictions affect the impact of sex education methods?

The study proceeded from two conceptual frameworks: a) that the concepts of parenting and adolescence sexual and reproductive behavior are social and cultural constructs, reflecting both gender and power relations and b) that gender and power relations between the genders within the family and the larger society play a significant, if not the most significant, role in determining the efficacy of which type of parenting style in the upbringing of young people. It is the view of this researcher that both parenting styles and gender relations play a crucial role in adolescent sexuality and its differential consequences for adolescent girls and boys. Hence this study devoted a considerable attention to both frameworks. The study also sought to identify socio-cultural and environmental/structural factors influencing teenage pregnancy and other sexual and reproductive activities. Thus, such factors as socialization (the internalization of cultural beliefs and practices), poverty, gender inequality, parental and peer influence, opportunities for education and employment were studied. In addition, internal factors, such adolescents' personal beliefs and convictions or agency were examined.

This study hypothesized that parental style provides a useful explanatory framework for understanding how parents prefer to as well as actually interact with their children. At the same time, these preferences may lead to differences in attitudes and perceptions of parental roles as these parents develop parenting strategies with regard to specific threats to their children.

Four hypotheses regarding sexual and reproductive behavior and parenting styles were examined.

a) Adolescents whose parents are authoritarian will report higher levels of sexual discipline and sexual health.

b) Adolescents whose parents are permissive will report lower levels of sexual discipline and sexual health. 
c) Authoritarian parents will report higher levels of involvement in their children's sex education.

d) Permissive parents will report lower levels of involvement in their children's sex education.

In addition, the researcher sought to determine if adolescents' agency or free will, peer pressure, teachers' influence and exposure to the mass media play any roles in reinforcing or cancelling parenting styles.

\section{Literature Review}

In Ghana, empirical studies on adolescent and reproductive health are a fairly recent phenomenon. This may be due to the fact that first, until 1969 when Ghana adopted a national population policy, population issues were not favourite topics for social scientists. A second plausible explanation may be that as a typically traditional society, issues relating to sex and sexuality are not for public discourse. Possibly, therefore, many local social scientists have shied away from studying reproductive health, especially of the youth. As would be expected, much of the available material on this topic dates from the 1970s. Even though the legal age at first marriage is low (18 years) the youth engage in premarital sex for various reasons. Poverty and lack of attention from caregivers are significant contributors to early sexual relationships (Afenyadu and Goparaju, 2003).Monies that the youth receive are used to provide basic needs such as school fees, food and to pay medical bills. Another study revealed that, one-third (33\%) of the sexually-active female adolescents and 13 percent of the sexually-active males reported that they had had sex for a financial reward.

Early sexual relationships also result from peer pressures, the need for pleasure and financial difficulties.( Population Impact Project, 1995) The GDHS records that $62 \%$ of males and $38 \%$ of females engaged in sexual relationships because they just wanted to do so. In addition, a significant number of females get involved in sexual activities due to coercion or force; $2 \%$ of males and $12 \%$ of females claimed they were coerced to have sex while $0.5 \%$ of males and $0.6 \%$ of females were forced by a family member.

In Ghana only $16 \%$ of teenage girls can correctly indicate when a woman is most fertile and likely to become pregnant. However, some reported having used periodic abstinence which is the most preferred contraceptive method among the youth (Gyekye, 1996; Tweedie \& Witte, 2000; Agyei et al., 2000; Glover et al, 2003). The contraceptive prevalence rate among young women between the ages of $15-19$ was $19 \% ; 13$; \% of them used modern methods while $12 \%$ used traditional methods. This may also be due to the lack of information and youth-friendly services.

One study about Southern Ghana reported that young girls used harmful but cheaper methods to terminate pregnancies. (Saller, 2001) 
Writing on abortions in a Kwahu town in the Eastern Region of Ghana, Bleek and Asante-Darko revealed the modes and methods -both allopathic and indigenous- employed in the exercise.(Bleek and Asante-Darko, 1996) The allopathic methods included a wide range of tablets and other medicines while the indigenous methods included a number of herbal preparations. Reasons for inducing abortion range from socio-cultural to psychological. (Senah, 2003). (Also see Awusabo-asare and Biddlecom 2006; Awusaboasare, , Bankole, and Kumi-kyereme,, 2008)

Traditionally, sexuality was not a topic for children or for public discussion, and was not a topic discussed between parents and their siblings. Indeed, as some studies have shown, girls were 'educated' on their reproductive behaviour only on the attainment of menarche or in initiation rites into womanhood. (Sarpong, 1974; Huber, 1993; Steegstra, 2004) Thus, communication between parents and their children, especially on family life education, is very poor.

Today, although many parents, especially the elite, believe that family life education must be given to their wards, there is no agreement as to when this must begin and the content of such education. Thus, for the youth, the main source of information on reproduction is the Mass media.( Masoloko T, et a, 2003) In conclusion, the little work done on adolescent sexuality has shown that the youth are actively engaged in sexual activities while because of tradition, their educational needs on reproductive health are largely unmet by the society. Consequently, in the absence of any adequately planned direction, the youth depend on their peers and the mass media for guidance.

\section{Parenting Styles and Sexual and Reproductive Behaviour}

Family environment counts as one of the most factors impinging on youth sexual behavior, yet remains poorly researched in sub-Saharan Africa, adding that a proper understanding of family influences could improve the efficiency of reproductive health (RH) interventions ((Dimbuene \& Defo, 2011, p. 1) The study "Family Environment and Premarital Intercourse in Bandjoun (West Cameroon)" revealed a "stronger parent-child relationships and higher levels of parental control decreased the risk of premarital intercourse.” (Harrison, Cleland, Gouws, \& Frohlich, 2005, as citied in Dimbuene and Defo).

Lax or lack of proper parental or guardian care and premarital sexual activity during adolescence are strongly correlated. Premarital sexual activity and nascent adulthood triggers a plethora of deleterious outcomes in many African societies, including unintended pregnancies, illegal abortions, sexually transmitted infections (STIs), and HIV/AIDS Dimbuene and defo (2011, p.2). Compounding the problem is the fact that "first sex among 
adolescents and young adults in SSA is often unprotected.”(Ibid.) rapid urbanization, western cultural influences, poverty, and eroding traditional ethos and cultural practices have all "conspired" to reduce effective parental supervision and control of their adolescent children. For this reason, some research has noted that first sexual experience among teens and youth adults constitutes a huge social problem and a serious public health issue. (Ibid.)

A balance of positive and flexible parenting methods is crucial to a child's overall emotional, cognitive and mental development. Good parenting forms the bedrock for adolescents and young adults acquiring good moral and ethical behavioral traits. (Darling and Steinberg, 2012; Grusec, 2006; Maccoby and Martin, 1983; Bornstein and Bornstein, 2014).

\section{Recent Research Results}

Multiple lines of research have established a link between authoritative parenting - a parenting style by which parents balance demandingness and responsiveness--with higher social competencies in children. According to recent research findings, "children of authoritative parents possess greater competence in early peer relationships, engage in low levels of drug use as adolescents, and have more emotional well-being as young adults.” (Bornstein and Bornstein, 2014:1).

Commenting on authoritarian and permissive styles of parenting, Bornstein and Bornstein (2014) have observed that the two are believed to be diametrically opposed, "neither style has been linked to positive outcomes, presumably because both minimize opportunities for children to learn to cope with stress." The researchers contend that "too much control and demandingness" tend to limit children's opportunities to make decisions for themselves or to make their needs known to their parents, while children in permissive/indulgent households may lack the direction and guidance necessary to develop appropriate morals and goals.”

Bornstein and Bornstein (2014) maintain that while recent research appear to be robust, their applicability across cultures and environments is questionable. This is because many of the studies focus on white, middleclass children and families, but children with different ethnic/racial/cultural or socioeconomic backgrounds may fare better under different types of guidance.

"Ethnic and cultural differences must also be taken into account in studying the effects of parenting styles on child social development. It is difficulty to escape social pressures that judge some parenting styles to be better, usually those that reflect the dominant culture. Authoritarian parenting, which is generally linked to less positive child social outcomes, tends to be more prevalent among ethnic minorities. In Asian ethnic families, authoritarian parenting is linked to positive social outcomes and academic 
success, due in part to parenting goals and training specific to Asian-origin families.” Bornstein and Bornstein, 2014: 2)

What remains to be established is the link between parenting styles and reproductive behaviour, particularly in adolescent females and males. This research sought to do just that.

\section{METHODOLOGY}

The research design used both quantitative and qualitative methods, including focus group discussions, out-of-school adolescents, teachers, parents, and community opinion leaders.

\section{The Qualitative}

Quantitative and qualitative research methods were used to collect data. The quantitative and qualitative research instruments were designed in such a way that they complemented each other. The key qualitative research method used focus group discussions with community opinion leaders, teachers, as well as in-and out-of-school adolescents. Individual sex histories were taken from a cross-section of adolescents, primary caregivers and community opinion leaders.

Separate focus group discussion guides were prepared to guide the discussions with in-school adolescents, including Senior Secondary School (SSS) and Junior Secondary School (JSS) students, out-of-school adolescents, teachers, and community opinion leaders. Information was also gathered from secondary sources, including head teachers/masters, the Suhum Government Hospital, and the District Assembly.

\section{The Quantitative}

For the quantitative research, three questionnaires were designed and applied as instruments for data collection. One questionnaire was directed to adolescents (both in-school and out-of-school), and to community opinion leaders. For the in-school adolescents, the questionnaire was administered at both the SSS and JSS levels. The adolescent questionnaire was administered to representative samples of adolescents and community opinion leaders (members of the local assembly). The research employed a combination of snowball sampling and random sampling techniques. Snowball sampling method was used in recruiting out-of-school teenagers. This was done with the assistance of mostly teachers and the research assistants, but some community leaders (local assembly members) also helped. . Random sampling techniques were used in recruiting in-school teenagers. With the assistance of teachers and two Ghanaian research assistants (themselves teachers), every third student in a row of 12 students were called and sent to a computer lab in the case of Suhum Senior Secondary School and a vacant 
classroom at Suhum Junior Secondary School. In all, 250 adolescents were selected. Out of this number, 217 actually participated in and returned their questionnaires. Most of the unreturned questionnaires were from the out-ofschool participants. Twelve of the questionnaires from Suhum Junior Secondary Schools and five from Suhum Presbyterian Senior Secondary School were returned blank or partially completed.

\section{RESULTS}

\section{Demographics}

This study involved three participant groups: Newtown Junior Secondary School (NJSS), Suhum Presbyterian Senior Secondary School (SPSSS), and Out-of-School Teenagers (OOS). Detailed demographic questions were asked in the survey pertaining to their age, sex, personal history, family background and so forth. It is imperative that such questions were asked because it will provide a better picture of the population that is being surveyed.

\section{Participants}

\section{Group 1: Newtown Junior Secondary School (NJSS)}

$\begin{array}{llll} & \text { Males } & \text { Females } & \text { Overall } \\ \text { Number of Participants } & 22 & 15 & 37 \\ \text { Age Range: } & 10-18 & 10-18 & 10-18 \\ \text { Mean Age: } & 14.95 & 14.80 & 14.89\end{array}$

\section{Group 2: Suhum Presbyterian Senior Secondary School (SPSSS)}

Number of Participants

\section{Males}

79

Age Range:

Mean Age:

*For 78 participants, one did not state their age

**For 61 participants, one did not state their age

*** For 139 participants, two did not state their age

\section{Females}

62

$14-20$

$17 * *$
Overall

141

$9-25$

$17.49 * * *$

\section{Group 3: Out of School (OOS)}

\begin{tabular}{llll}
\hline & Males & Females & Overall \\
Number of Participants & 19 & 20 & 39 \\
Age Range: & $14-19$ & $14-19$ & $14-19$ \\
Mean Age: & 17.26 & 17.1 & 17.18
\end{tabular}

Across all three groups, Christianity was the dominant religion: NJSS 97.3\%, SPSSS 95.7\%, and OOS $84.6 \%$. 


\section{Parents and Guardians}

Parents and guardians serve an important role in the lives of the teenagers. They are both their caregivers and role models. Parental background questions were included in the survey. These question included age, marital status, level of education, and religion.

Parents of Newton Junior Secondary School Students

Number of Responses

$\begin{array}{ll}\text { Father } & \text { Mother } \\ 23 & 23 \\ 30-70 & 25-60 \\ 46.04 & 41.39\end{array}$

Age Range:

Mean Age:

46.04

41.39

Education:

$\begin{array}{lll}\text { Elementary } & 32.4 \% & 32.4 \% \\ \text { Secondary } & 43.2 \% & 21.6 \% \\ \text { Post-Secondary } & 5.4 \% & 2.7 \% \\ \text { No formal Education } & 10.8 \% & 29.7 \% \\ \text { No Answer } & 8.1 \% & 13.5 \%\end{array}$

Parents of Suhum Presbyterian Senior Secondary School Students

Number of Responses

Father

95

$34-78$

50.28

Mean Age:

Education:

Elementary
Secondary
Post-Secondary
No formal Education
No Answer

$29.8 \%$

$36.2 \%$

$22.0 \%$

$9.9 \%$

$2.1 \%$

\section{Mother}

112

25-67

44.06

$38.3 \%$

$25.5 \%$

$9.9 \%$

$22.7 \%$

$3.5 \%$

\section{Parents of Out of School Teenagers}

Number of Participants

\section{Father}

Age Range:

30

$39-71$

50.83

Mean Age:

Education:

Elementary
Secondary
Post-Secondary
No formal Education
No Answer

$\begin{array}{ll}59.0 \% & 71.8 \% \\ 30.8 \% & 15.4 \% \\ 7.7 \% & 2.6 \% \\ 2.6 \% & 10.3 \% \\ 0.0 \% & 0.0 \%\end{array}$

Mother

30

34-53

42.87

$71.8 \%$

$2.6 \%$

$0.0 \%$ 
With similar results compared to their children, across all three groups, parents' religion was predominantly Christianity: NJSS parents $92.6 \%$, SPSSS parents $92.9 \%$, and OOS parents $85.9 \%$. The above data also showed that a very small percentage of parents achieved an education level higher than secondary school. This is especially true for the mothers in all three groups. We may infer that the gender inequality in the education level of parents was due in part to the fact that mothers were more likely to have had to put an end to their academic career in order to care for their children. A further analysis of the data shows that the percentage of mothers who have no formal education is more than double that of their male counterpart in all three groups. This further supports the inequality of education between genders and can be seen mirrored in the greater number of males who are in school in this study compared to the females who are in school.

\section{Sexually Active?}

Since this study was centered on finding more about sexual and reproductive health of teenagers in Suhum, it was obvious that one of the questions pertain to sexual activity. This pivotal question served as the gateway leading to other questions relating to their sexual practices and beliefs. Participants were therefore questioned if they were sexually active.

It was found that between males and females across all three groups, the highest percentage of sexually active individuals were from the Out of School (OOS) group. From the OOS group, $78.9 \%$ males and $95 \%$ females answered yes to being sexually active compared to less than $50 \%$ from the rest of the groups with the lowest being the NJSS females at only $20 \%$.

\section{Safe Sex Practices}

Of great concern, aside from the number of teenagers who are sexually active, is the topic of safe sex practices. There is currently no cure for AIDS and the only method of combating this disease is through prevention. In addition to preventing STDs, safe sex also means preventing unwanted pregnancy.

The data showed that the greatest number of males reporting that they practice safe sex were from the OOS group. While amongst females, there were no significant differences between the percentage of individuals who reported practicing safe sex. It was also found that across all groups, condoms was the dominating contraceptive of choice, although other forms were also practiced such as foam (3.8\% SPSSS males), the pill (27.3\% SPSSS females), and withdrawal (50\% NJSS males). It should be noted that withdrawal, although considered as a form "safe sex" practice, is the least effective. This is hugely due in part to the fact that before a male can feel himself needing to ejaculate, he may already have discharged a substance 
called pre-ejaculate or more commonly known as pre-cum. This substance is capable of impregnating a female and, because it is a form of body fluid, is also capable of transmitting STDs.

Overall, the majority of the participants indicated that they do practice safe sex. This is contradictory to the widely received global message that AIDS/HIV is an epidemic in Africa. Looking at other components of the data, we see that condoms rank first as the indicated contraceptive being used, but most of the respondents indicated that they only use them sometimes. Adding this extra bit of information is significant in that the "sometimes" that condoms aren't being used, gives the disease a window of opportunity to being passed on to the second person. Also, the effectiveness of condoms lies not only in its frequency of usage but also in its method of usage. According to the Centers for Disease Control and Prevention (2003), the correct usage of condoms is vital, and incorrectly using condoms can lead to the transmission of STDs. (Centers for Disease Control and Prevention (2003)

The data comparing the occurrence of STIs amongst the participants revealed that the groups that the JSS Males (57.1\%) and OOS Females (21.1\%) yielded the most STDs. JSS Females, however, had no occurrence of STDs. This is intriguing, in that JSS Males are infected, yet females are not. But when the participants answered questions regarding same sex activity, we see that $13.6 \%$ of JSS males answered yes to having engaged in same sex activity while amongst JSS Females, there is none. So is it safe to conclude that STDs are only passed between males in the JSS group?

\section{Age of First Intercourse}

The age of an individual's first sexual intercourse is relevant, in that the younger individuals are often unaware of the risks associated with unprotected sex. In finding out when individuals are first engaging in sexual intercourse, educational programs can therefore be tailored and aimed at these groups. Current sexual health programs may be less effective if they were delivered to those who have already been engaging in sexual activities since an earlier age and/or have been already exposed to STDs. Among the male participants, all of those who were sexually active in the NJSS group report that they engaged in sexual intercourse before the age of $13(100 \%)$. This was also predominantly true for those in the OOS group (53.3\%). While in the SPSSS group, $51.4 \%$ report to having their first sexual intercourse before the age of 16 .

Amongst the female participants, across all three groups, NJSS, SPSSS, and OOS, the majority of individuals (66.7\%, 61.1\%, and 68.4\% respectively) reported to having had their first sexual intercourse before the age of 16 . 


\section{Factors Influencing Sex}

Knowing the percentage of teenagers who are sexually active and at what age they were when they had their first sexual intercourse, is relevant in finding out what the reasons are for them engaging in sexual activities. In summarizing the responses from the participants, it was more fitting to combine all the responses across the groups into one illustrative chart.

Peer Pressure and Peer Pressure from friends, classmates, etc. accounts for the majority of responses (41.1\%) from the participants. Indeed, it can be predicted that this would be the outcome since peer pressure, in itself, has lent itself to manifest other destructive behaviors amongst teenagers such as smoking, drug use, and truancy. Money and financial reward make up another bulk (20.2\%) of the responses. Devising a strategy to combat these factors would require both teenager and peer education, in addition to addressing the economic disparity that plague Africa.

\section{Pregnancy and Abortion}

In addition to the concern of STDs amongst African teenagers, teenage pregnancy is also a problem. Teenage females who are pregnant may face dropping out of school to care for their baby and lack of education which, leads to underpaid labour. Males, who if so choose to provide for their family, may also face the reality of dropping out of school in order to support their new family. But when looking at the responses, we can see that the ratio of males whose wife/girlfriend is currently pregnant is relatively low. The highest lies in the out of school group at $20.0 \%$.

Next, amongst the females, we see a very similar trend in comparison to the male respondents. The majority of females are not pregnant and again, the highest is in the out of school group at 15.8\%. More alarmingly, $57.9 \%$ of the OOS females have been pregnant before and $40 \%$ of the OOS males have impregnated someone before.

\section{Sex Education}

The source of teenage sex education is an integral component in understanding the trends found in the data. Advertisements from the mass media-TV, radio, and magazines - are often viewed as providing an over promiscuous view on sexuality. Sex sells. Therefore, it is also important to know where teenagers are getting their information and thus, by augmenting that source to provide more relevant information and a more realistic view to these teenagers. With a reliable educational source, they can better use the available information to their advantage. Amongst all respondents, the top four sources of safe sex education are television (14\%), radio (13\%), mothers (13\%), and teachers (13\%). 


\section{Parenting Style}

Parenting style is an obvious question when trying to relate to teenage behavior. Parents who "slack off" in their parental approach are perceived as being not caring or giving their children too much freedom. If we follow this belief, we should see some correlation between parenting style and deviant behavior-in this case, destructive sexual behavior.

The data showed that most parents fall in the "very strict" parental style category. The lowest percentage between the three groups of very strict parents belongs to the OOS group. The OOS group also has a more evenly distributed parental style of both fathers and mothers, whereas in the SPSSS group, we see a very low percentage of parents falling in the "not strict at all” category.

\section{Summary and Conclusion}

Analysis of the data obtained from the questionnaires, provides a clear picture of sexual and reproductive behaviours of the teenagers surveyed. However, the relationship between parental styles and teens' sexual reproductive behaviours is much less clear. First of all, most of the teenagers in this study first engaged in sexual activity at a very young age. This is very important in designing educational programmes and in deciding who the targeted audiences are. Having established that the teenagers in question engage in sexual activity very early, the question then arise as to why? It is evident from the study that the problems mainly reside in the issue of poverty and lack of education. The majority of the teenagers surveyed engaged in sexual activity due to money and financial reward. Sexual activities which stem from fulfilling monetary needs translate into high risk behavior because it means having sex with numerous partners. One only needs to find those who are willing to pay for the "service," as it were. Increased number of partners greatly increases the chance of contracting sexually transmitted diseases. There is also the issue of compliance. The "service provider" who is in desperate need of money is in no position to negotiate the issue of contraceptive use. They are most often at the mercy of their buyer.

The overall trend appears to be that the "sexual deviants" are from the out-of-school group. This is further supported by the data collected from the adults. Therefore, we may further this study by finding out why these teenagers have dropped out of school. Is there a correlation between community support, a healthy parental relationship, and sexual health?

While the link between parental styles and teens' reproductive and sexual behaviours is a bit muddled in this study, it is clear that the socio-economic status and the pervasive poverty among parents prevented most parents to provide the needed sex education for their children. As most of the 
participants in the focus group discussions averred, their parents spend less time with them at home, as they work from “dusk to dawn" providing for the family. It can be surmised therefore that while parents are mostly strict disciplinarians, the lack of time prevents them from effective control and supervision of their teenage children. In other words, parents can be strict disciplinarians and still lose control of their children's sexual and reproductive behaviours.

\section{References:}

Abdulraheem IS and Fawole OI. (2009). "Young People’s Sexual Risk Behaviours in Nigeria.” In: Journal of Adolescent Research 2009; 24(4): 505-527.

Afenyadu D and Goparaju L. (2003).Adolescent Health and Sexual Behavior in Dodowa, Ghana. The Centre for Development and Population Activities, 2003; 10, 14.

Awusabo-asare, K. and Biddlecom, A. (2006) Adolescent Sexual and Reproductive Health in Ghana: Results from the 2004 National Survey of Adolescents. Occasional report No. 22

Awusabo-asare, K., Bankole, A., and Kumi-kyereme, A. (2008) "Views of adults on adolescent sexual and reproductive health: Qualitative evidence from Ghana.” Occasional report No. 34.

Bleek W and Asante-Darko N. (1986). "Illegal Abortion in Southern Ghana; Methods Motives and Consequences.” In: Human Organization 1986.

Bornstein, Lea and Bornstein, Marc, H. (2014). "Parenting Styles and Child Social Development.” http://www.childencyclopedia.com/sites/default/files/textes-experts/en/654/parenting-stylesand-child-social-development.pdf Retrieved on January 29, 2017

Buga GA(1996).. Sexual behavior, contraceptive practice and reproductive health among school adolescents in rural Transkei. In: South African Medical Journal 1996; 86(5): 523-527.

Centers for Disease Control and Prevention. Fact Sheet for Public Health Personnel: Male Latex Condoms and Sexually Transmitted Diseases, 2003.

Day, RD.(1992). "The transition to first intercourse among racially and culturally diverse youth.” In: Journal of Marriage and Family 1992; 54: 749_ 776.

Defo BK and Dimbuene Z. (2011).”Timing of Premarital Intercourse in Bandjoun (West Cameroon).” In Arch Sex Behav 2011; 41: 351-361.

Glover, E.K., Bannerman, A., Wells Pence, B. (2003) "Sexual health experiences of adolescents in three Ghanaian towns.” International Family Planning Perspectives, 29(1), pp.32-40. [Online] Available from: http://www.ncbi.nlm.nih.gov/pubmed/12709310 Retrieved on April 3, 2012 
Ghana Statistical Service (GSS), Noguchi Memorial Institute for Medical Research (NMIMR), and ORC Macro. 2004. Ghana Demographic and Health Survey 2003. Calverton, MD: GSS, NMIMR, and ORC Macro.

Ghana Statistical Service and Macro International. Ghana Demographic and Health Survey, 1998.

Grusec JE and Hastings PD, (2006). Handbook of socialization: Theory and research. New York, NY: Guilford Press; 2006.

Gyekye K. (1996). African Cultural Values: An Introduction. Accra, Ghana: Sankofa Publications, 1996.

Harrison A, Cleland J, Gouws E and Frohlich F. (2005). "Early sexual debut among young men in rural South Africa: Heightened vulnerability to sexual risk? “ In: Sexually Transmitted Infections 2005; 81: 259-261.

Huber H. (1993).The Krobo: Traditional Social and Religious Life of a West African People. Fribourg, Sitzerland: St. Paul's Press.

Kabiru CW and Orpinas P. (2009). Correlates of Condom Use among Male High School Students. In: Journal of School Health 2009; 79(9): 425-431.

Lauritsen JL, Sampson RJ and Laub JH. (1991).”The link between offending and victimization among adolescents.” In: Criminology 1991; 29: 265-292.

Maccoby EE, Martin JA (1983). Socialization in the context of the family: Parent-child interaction. In: Hetherington EM, ed. Socialization, personality, and social development. New York, NY: Wiley; 1983:1-101. Mussen PH, ed. Handbook of child psychology. 4th ed; vol 4.

Masoloko $\mathrm{T}$, et al. (2003).The role of parenting practices in poverty reduction. http://www.gla.ac.uk/centres/cradall/docs/Botswanapapers/masolokofinal_48.pdf. Retrieved on January 29, 2017.

Mwaluko G, Floyd S, Nyondo A and Crampin A. (2005). HIV and mortality of mothers and children: evidence from cohort studies in: Uganda, Tanzania, and Malawi. In: Epidemiology 2005; 16(3): 275-180.

Otieno FO, Ndivo R, Oswago S, Pals S, Chen R, Thomas T, Kunneke E, Mills LA, McLellan-Lemal E.(2015). Correlates of prevalent sexually transmitted infections among participants screened for an HIV incidence cohort study in Kisumu, Kenya. Int J STD AIDS. 2015 Mar;26(4):225-37.

Population Impact Project. Adolescent Fertility and Reproductive Health in Ghana, 1995; 6.

Sarpong PA. (1974).Girls Nubility Rites in Ashanti. Tema: Ghana Publishing Corporation.

Saller A.M. (2001). "Sexual risk taking in the era of HIV/AIDS: Case study of adolescents resident in Ketu South, upper Denkyira and Offinso Electoral Constituencies in Ghana." Vancouver:: University of British Columbia, Diss.1

Senah K. (2003). Maternal Mortality in Ghana: The Other Side. In Research Review 2003; 19(1): 47-55. 
Sia D, Onadja Y, Hajizadeh M, Heymann SJ, Brewer TF, Nandi A. BMC Public Health. (.2016). What explains gender inequalities in HIV/AIDS prevalence in sub-Saharan Africa? Evidence from the demographic and health surveys. Nov 3; 16(1):1136. Epub 2016 Nov 3.

Steegstra M. (2004). Resilient Rituals: Krobo Initiation and Politics of Culture in Ghana. Zugl: Nigmegen, Univ., Diss, 2004.

The Daily Graphic. (1998). Teenage pregnancy in Suhum tops national average.4.

The Daily Graphic. Suhum records more teenage pregnancies. 2002. Available at http://www.modernghana.com/news/28411/1/suhum-recordsmore-teenage-pregnancies.html Accessed 8/8/2008

The Daily Graphic Online. (2014). Eastern Region records 13000 plus pregnant students - Graphic Online Retrieved on January 27, 2017.

UNAIDS and WHO Report on the global AIDS epidemic. UNAIDS, Geneva, 2008

Upchurch D, Levy-Storms L, Sucoff CA and Aneshensel CS. (1998). "Gender and ethnic differences in the timing of first sexual intercourse." In: Family Planning Perspectives 1998; 30(3): 121-127.

Whitbeck L, Hoyt D, et al. (1992). "Parental support, depressed affect, and sexual experiences among adolescents.” In: Youth and Society 1992; 24(2): 166-177.

Wu LL and Martinson. (1993). "BC. Family Structure and the Risk of a Premarital Birth.” In: American Sociological Review 1993; 58: 210-232.

Young NL, Williams JI, Yoshida, KK and Wright JG (1991). "Measurement properties of the Activities Scale for Kids.” In: Journal of Clinical Epidemiology 1991; 53: 125-137.

Zaba B, Whitworth J, Marston M, Nakiyingi J, Ruberantwari A, Urassa M, Issingo R, (2005)."HIV and mortality of mothers and children: evidence from cohort studies in Uganda, Tanzania, and Malawi.” Epidemiology. 2005 May;16(3):275-80. Retrieved on January 29, 2017. 